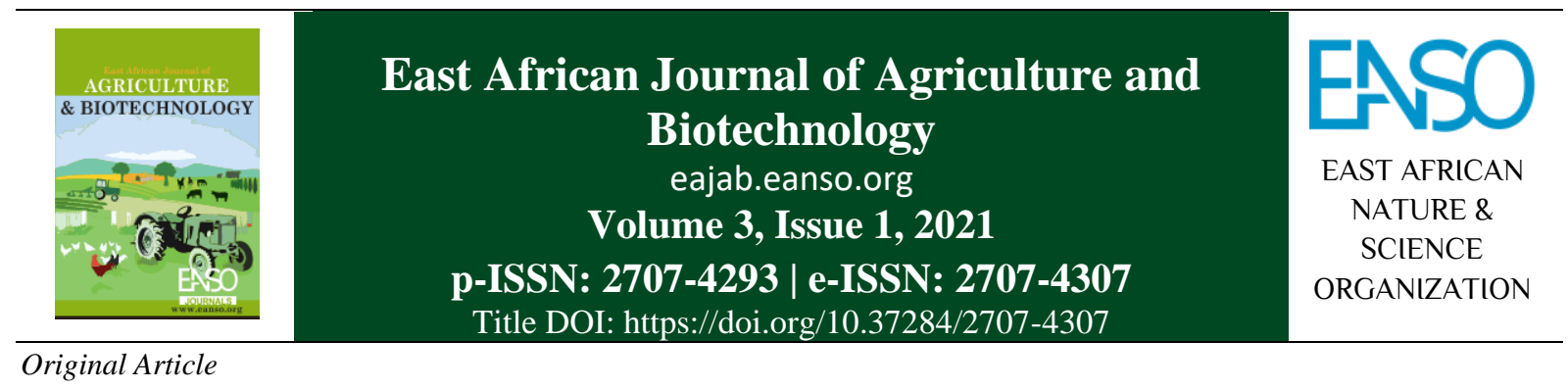

\title{
Potential of Human Urine as a Nutrient Medium for the Biomass Production of Microalga Scenedesmus sp.
}

\author{
Abebe Muluye ${ }^{l,}$ Berhanu Sali ${ }^{1}$, Blien Bahta ${ }^{1}$, Birtukan Melese ${ }^{1}$, Bethel Girma ${ }^{1}$, Misrak \\ Kebede ${ }^{1}$, Muluken kebede ${ }^{1} \&$ Dr. Arumuganainar Suresh ${ }^{1,2 *}$ \\ ${ }^{1}$ College of Biological and Chemical Engineering, Addis Ababa Science and Technology University, Addis Ababa-16417, \\ Ethiopia. \\ ${ }^{2}$ Suguna Foods Private Limited, Udumalaipettai-642126, Tamil Nadu, India \& Department of Biotechnology. \\ ORCID ID: https://orcid.org/0000-0002-3193-0345; Correspondent, Email: suresha@ sugunafoods.com
}

Article DOI: https://doi.org/10.37284/eajab.3.1.409

\section{Date Published: ABSTRACT}

14 September 2021

Keywords:

Autotrophs;

Biomass;

Human urine;

Microalgae;

Nutrients;

Scenedesmus
Microalgae have value-added chemicals, but their biomass production is costly due to the expensive nutrient chemicals. Meantime human urine (HU) is considered wastewater and has basic nutrients for autotrophs. This study tested the potentials of being cheaply available in HU as a nutrient source for the biomass production of microalga Scenedesmus sp. HU was collected, sterilized, and made different dilutions. Microalga of Scenedesmus sp., was isolated from the urine contaminated site, purified, inoculated into the $\mathrm{HU}$ medium, and incubated under Sunlight for 7 days at $25^{\circ} \mathrm{C}$. The maximum growth was observed in $15 \% \mathrm{HU}$ as $0.795 \mathrm{OD}_{670 \mathrm{~nm}}$ with $0.57 \mathrm{~g} / \mathrm{L}$ biomass production with a significant difference $(\mathrm{p}<0.01)$. The productivity of 81 $\mathrm{mg} / \mathrm{L} /$ day was reached. The concentrated urine of more than $20 \%$ was not supporting the growth of microalga. This study concluded that human urine can be used as a nutrient medium for microalgae growth at certain dilution.

35 This work is licensed under a Creative Commons Attribution 4.0 International License. 


\section{Graphical Abstract}

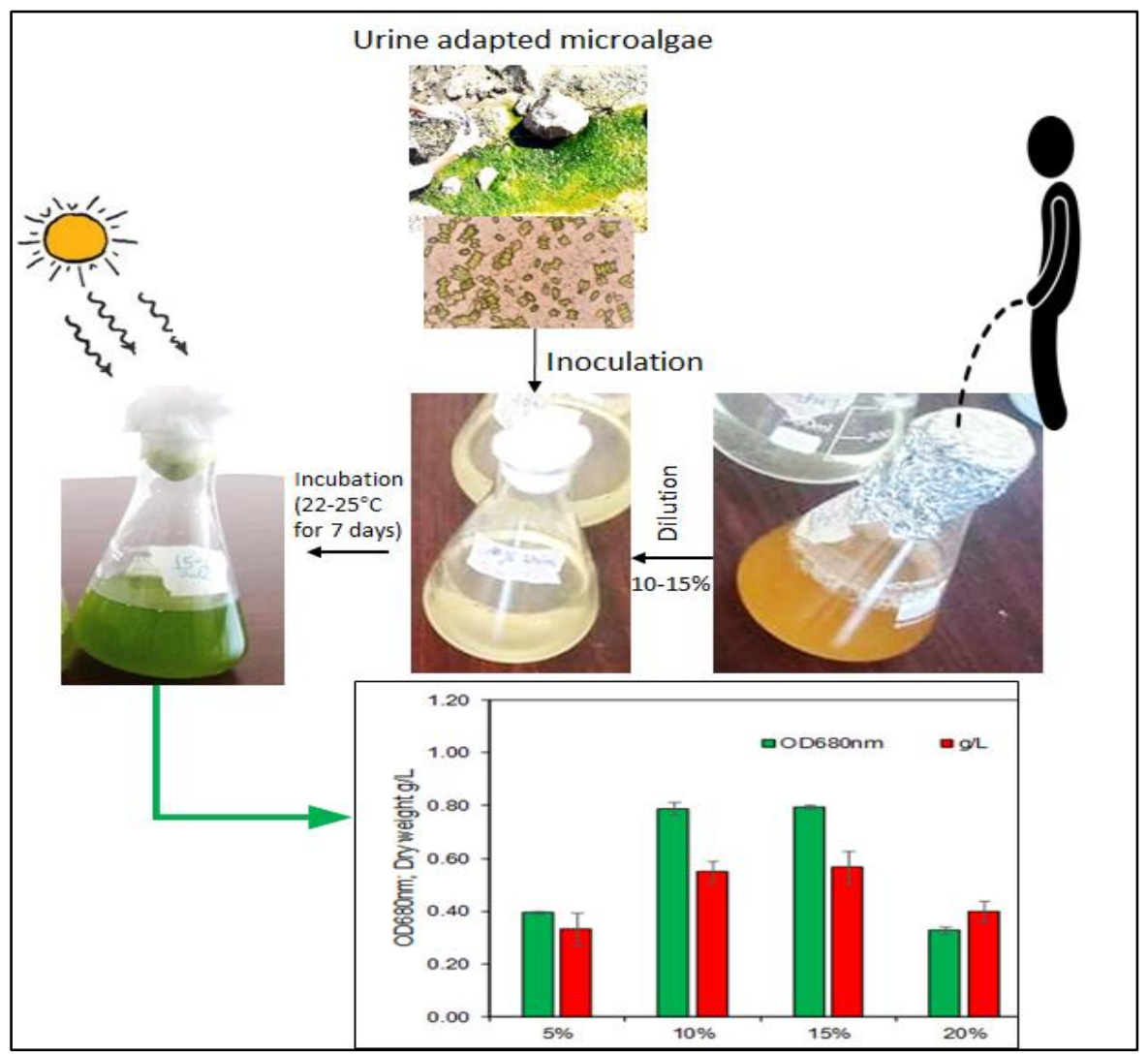

APA CITATION

Muluye, A., Sali, B., Bahta, B., Melese, B., Girma, B., Kebede, M., kebede, M., \& Suresh, A. (2021). Potential of Human Urine as a Nutrient Medium for the Biomass Production of Microalga Scenedesmus sp. East African Journal of Agriculture and Biotechnology, 3(1), 35-41. https://doi.org/10.37284/eajab.3.1.409

\section{CHICAGO CITATION}

Muluye, Abebe., Berhanu Sali., Blien Bahta., Birtukan Melese., Bethel Girma., Misrak Kebede., Muluken kebede., and Arumuganainar Suresh. 2021. "Potential of Human Urine as a Nutrient Medium for the Biomass Production of Microalga Scenedesmus sp". East African Journal of Agriculture and Biotechnology 3 (1), 35-41. https://doi.org/10.37284/eajab.3.1.409.

\section{HARVARD CITATION}

Muluye, A., Sali, B., Bahta, B., Melese, B., Girma, B., Kebede, M., Kebede, M. \& Suresh, A. (2021) "Potential of Human Urine as a Nutrient Medium for the Biomass Production of Microalga Scenedesmus sp", East African Journal of Agriculture and Biotechnology, 3(1), pp. 35-41. doi: 10.37284/eajab.3.1.409.

\section{IEEE CITATION}

A. Muluye, B. Sali, B. Bahta, B. Melese, B. Girma, M. Kebede, M. Kebede \& A. Suresh. "Potential of Human Urine as a Nutrient Medium for the Biomass Production of Microalga Scenedesmus sp”, EAJAB, vol. 3, no. 1, pp. 35-41, Sep. 2021.

\section{MLA CITATION}

Muluye, Abebe., Berhanu Sali., Blien Bahta., Birtukan Melese., Bethel Girma., Misrak Kebede., Muluken kebede., and Arumuganainar Suresh. "Potential of Human Urine as a Nutrient Medium for the Biomass Production of Microalga Scenedesmus sp". East African Journal of Agriculture and Biotechnology, Vol. 3, no. 1, Sep. 2021, pp. 35-41, doi:10.37284/eajab.3.1.409.

\section{NTRODUCTION}

Microalgae are under the limelight for their valueadded products (food, feed, fuel, bioremediation, medicine, and cosmetics) (Levasseur et al., 2020;
Suresh and Benor, 2020). However, its marketable production is still in infancy due to the production costs and related drawbacks (Fasaei et al., 2018). Nutrients are the main cost contributor for the growth of microalgae (34\% in total cost) 
than harvesting (20-30\% in total cost) and followed by the processing for algal-based products (Xin et al., 2016; Fasaei et al., 2018). Specially, nitrogen and phosphorus are major nutrients for autotrophs, annually 100 million and 14 million metric tonnes are used in agriculture alone, and primarily $(80 \%)$ from synthetic inorganic fertilizers, respectively (Erisman et al., 2008, Liu et al., 2008). Nonetheless, recent estimates confirm that phosphate reserves are expected to be exhausted in 50-100 years (Cordell, D., 2009).

Urine is nutrient-rich, readily available form, sustainable, cheap, and can promote microalga growth (Suresh et al., 2019; Tuantet et al., 2014). Generally, urine is considered wastewater and volume generated at 0.8 to 2 litre per day and reach 500 litres annually for an adult, which releases $\quad 2.5-4.3 \mathrm{~kg}$ nitrogen, $0.7-1.0 \mathrm{~kg}$ phosphorus, and $0.9-1.0 \mathrm{~kg}$ potassium annually per adult (Kirchmann, H. and Pettersson, S., 1995). Besides, shortage of fresh water and nutrients reservoirs, it was suggested that the integration of microalgae production to remediation of wastewater is considered a more economic, sustainable, and eco-friendly option (Yang et al., 2011). Not many studies have used $\mathrm{HU}$ as the growth medium for microalgae cultivation (Adamsson, 2000; Feng et al., 2006; Yang et al., 2008 a,b; Chang et al., 2013; Tuantet et al., 2014; Jaatinen et al., 2019). Among previous studies, yet no clear picture that which concentration is optimum for the growth of microalgae, for instance, some found more concentrated (50\%) (Tuantet et al., 2014), others found more diluted $(<2 \%)$ and shown different biomass production (Feng et al., 2006; Chang et al., 2013). This difference was attributed to the algae strain used and the specific purposes. Besides, given the great diversity of microalgae, it was recommended that naturally adapted to a particular environment, and native species are potential candidates for the purpose (Wilkie et al., 2011; Gelebo et al., 2020). Hence, this study conducted the growth potentials of urine-adapted microalga (Scenedesmus sp.,) in HU, and find out the dilution factor, and supporting the fact of $\mathrm{HU}$ as an efficient growth medium for the viable microalgae biomass production. This preliminary work was an attempt to support the utilization of HU for sustainable biomass production through the utilization of nutrients in line with ecological sanitation practices.

\section{METHODS}

\section{Microalga Culture}

Microalga sample was collected from the restroom runoff at AASTU campus, building no. 71 , and inoculated into $100 \mathrm{~mL}$ Bold's Basal Medium (BBM). The inoculated flask was incubated under Sunlight at $25^{\circ} \mathrm{C}$ for 15 days. The grown culture was purified using the spread plate method and the genus was identified using a light microscope followed the manual of Janse van Vuuren et al., (2006). The purified culture was maintained in a $100 \mathrm{~mL}$ BBM medium.

\section{Human Urine Collection}

One litre of fresh urine sample was collected from the student's voluntary participants in a clean water bottle and mixed well. The collected urine was sterilized using autoclave, then diluted and used immediately.

\section{Experiment}

Sterilized urine was diluted with sterile distilled water from $0 \%, 5 \%, 10 \%, 15 \%, 20 \%$, and 100 $\%$. The $100 \mathrm{~mL}$ of the diluted HU medium was inoculated with $1 \mathrm{~mL}$ of 15 days BBM grown alga culture, and incubated under Sunlight at $25^{\circ} \mathrm{C}$ for 15 days. The flasks were mixed manually twice a day. After 7 days, $2 \mathrm{~mL}$ was used for optical density analysis at $\mathrm{OD}_{670 \mathrm{~nm}}$ using a spectrophotometer (Biochrom, Libra S80PC, UK), the $20 \mathrm{~mL}$ was used for dry weight. All experiment was performed in triplicate. The zeroday OD was measured $\left(\sim 0.100 \mathrm{OD}_{670 \mathrm{~nm}}\right)$. The oneway analysis of variance (ANOVA: single factors) was performed using Microsoft Excel to determine the differences between the treatments.

\section{RESULTS AND DISCUSSION}

Urine has basic nutrients for the growth of autotrophic organisms include plants and microalgae (Viskari et al., 2018; Suresh et al., 2019). Currently, those nutrients are polluting the ecosystem, not been effectively used, besides it is economical, available globally. Microalgae has many value-added chemicals and grow faster than plants, grow in any water, do not need arable land, and have many advantages over plants (Suresh and Benor, 2020). However, the production of microalgae biomass is costly, more in terms of cultivation, especially nutrients cost than others 
like harvesting and processing (Fasaei et al., 2018). For example, $34 \%$ of the cost is used for the nutrient chemicals such as urea, dipotassium phosphate, and micronutrients (Xin et al., 2016). It has been exhibited that focusing on boosting biomass productivity is more important rather than value-added chemicals. In this preliminary study, a Microalga sample collected from HU contaminated site was observed few genera (Scenedesmus sp., Diatoms, Chlorella sp., and Chlamydomonas sp.,) of microalgae in the raw sample as well as in the BBM grown culture (Figure la). However, the dominant group of microalgae was Scenedesmus sp.

Figure 1: Micrograph of microalgae sample collected from human urine contaminated site (a) and purified the dominated Scenedesmus sp., (b)

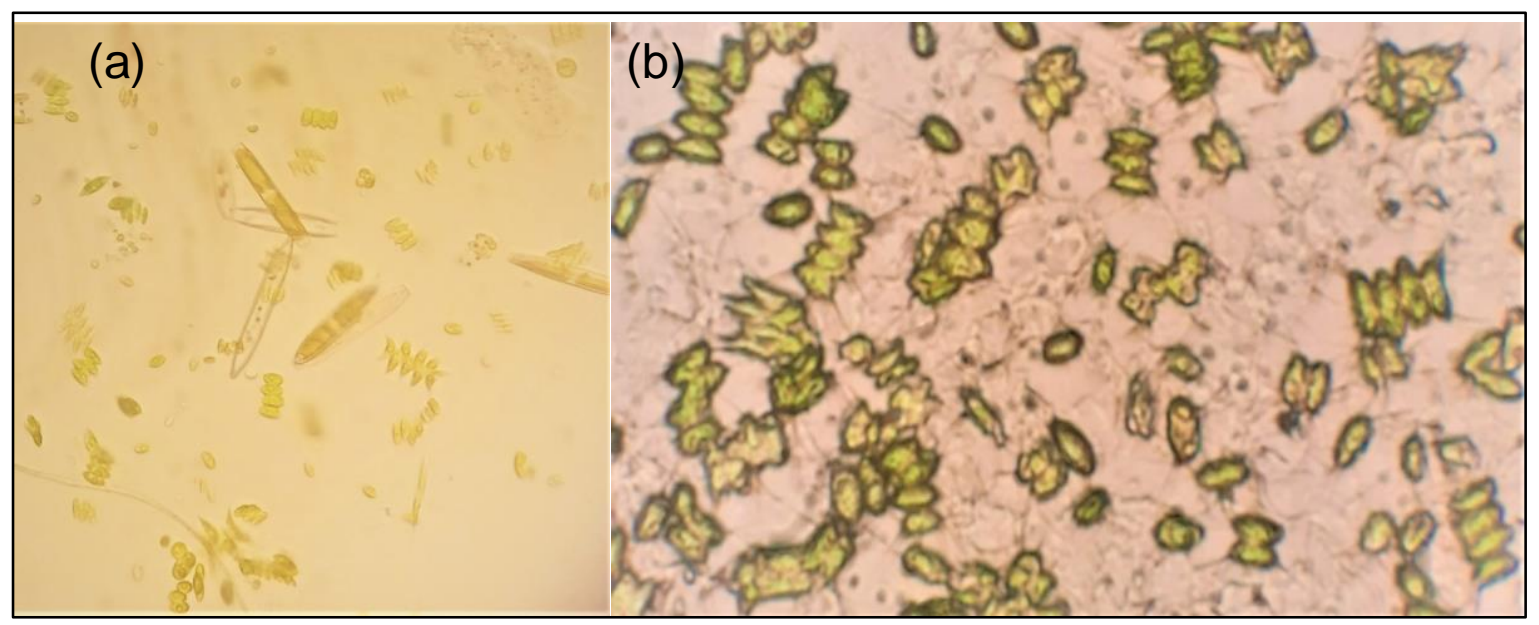

The purified Scenedesmus sp., (Figure 1 b) culture was used to check the growth potential in the diluted $\mathrm{HU}$ and observed copious growth in the specific dilutions (10 and $15 \%$ ) visibly (Figure 2).

Figure 2: Growth of microalga (Scenedesmus sp.,) in human urine at different dilutions for 7 days under Sunlight at room temperature

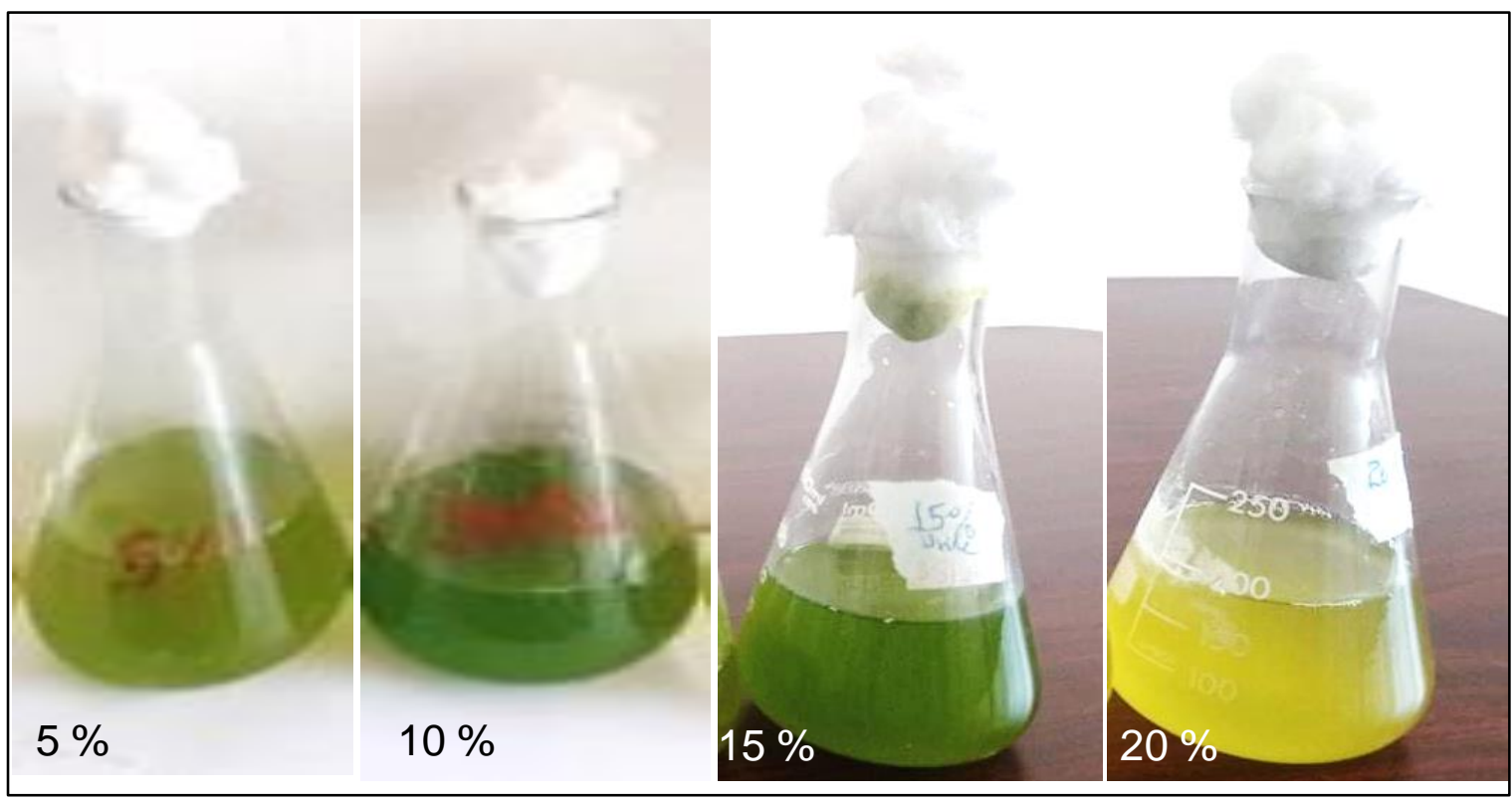

38 This work is licensed under a Creative Commons Attribution 4.0 International License. 
Figure 3: Biomass production of microalga Scenedesmus sp., in various concentrations of human urine alone, and Bold's Basal medium. (*denotes $p<0.01$ for comparison between the growth of Scenedesmus sp., in different dilution of human urine).

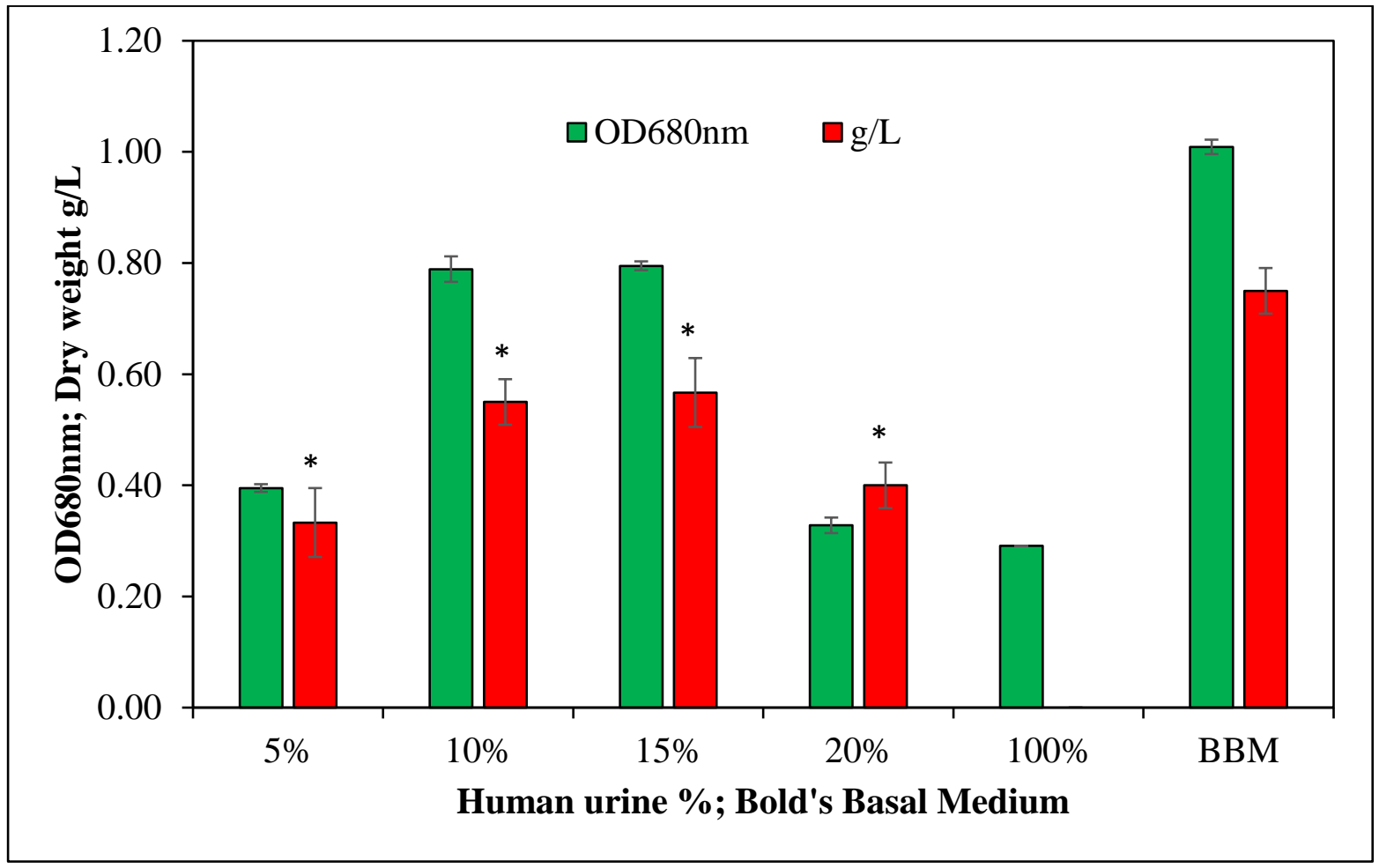

The maximum growth was reached at 0.795 $\mathrm{OD}_{670 \mathrm{~nm}}$ after 7 days in $15 \%$ human urine (Figure $3)$. The limited growth was observed $(0.395$ $\left.\mathrm{OD}_{670 \mathrm{~nm}}\right)$ in $5 \% \mathrm{HU}$ and increased to 0.789 $\mathrm{OD}_{670 \mathrm{~nm}}$ in $10 \%$ and reach a maximum of $15 \%$ $\mathrm{HU}$. The growth decreased to $0.328 \mathrm{OD}_{670 \mathrm{~nm}}$ at 20 $\% \mathrm{HU}$, and no growth was observed in the raw HU. Whereas the microalgae growth medium of BBM was shown $1.01 \mathrm{OD}_{670 \mathrm{~nm}}$ in the same conditions. The dry weight has also shown that the maximum of $0.567 \mathrm{~g} / \mathrm{L}$ and $0.75 \mathrm{~g} / \mathrm{L}$ biomass was produced in $15 \% \mathrm{HU}$, and BBM in 7 days of incubation, respectively. The productivity was reached 81 and $107 \mathrm{mg} / \mathrm{L} /$ day in $15 \% \mathrm{HU}$ and BBM medium, respectively. The growth was significantly $(\mathrm{p}<0.05)$ differed among the diluted HU medium.

In comparison with previous studies, (Adamsson, 2000; Jaatinen et al., 2019), this study found appreciably more biomass production in 7 days (Table 1). This copious growth was attributed to the alga culture used in this study was adapted to utilize the nutrients from the HU source as well as less diluted than previous studies. Previous studies also found that a similar concentration was good for microalgae biomass production using cow urine (Suresh et al., 2019). Moreover, this study found that the concentrated HU was not supporting the growth as little and no growth was observed in $20 \%$ and raw HU, respectively. Curiously, some studies found that the 1:1 diluted HU supported the growth of the microalgae of Chlorella sp., significantly, however, suggested 1:5 dilution was better (Tuantet et al., 2014). Further study is needed for the effective utilization of the nutrients in the $\mathrm{HU}$ in terms of optimization in specific concentrations, specific value-added strains and products, and cost analysis. 
Table 1: Comparison of microalgae biomass production in human urine

\begin{tabular}{llllll}
\hline $\begin{array}{l}\text { HU* } \\
\text { concentration }\end{array}$ & Microalgae & $\begin{array}{l}\text { Maximum } \\
\text { Biomass } \\
\text { (g/L) }\end{array}$ & Days & $\begin{array}{l}\text { Biomass } \\
\text { productivity } \\
\text { (mg/l/day) }\end{array}$ & Reference \\
\hline $5 \%$ & Scenedesmus sp. & $0.33 \pm 0.06$ & 7 & 48 & This study \\
$10 \%$ & Scenedesmus sp. & $0.55 \pm 0.04$ & 7 & 79 & This study \\
$15 \%$ & Scenedesmus sp. & $0.57 \pm 0.06$ & 7 & 81 & This study \\
$20 \%$ & Scenedesmus sp. & $0.4 \pm 0.04$ & 7 & 57 & This study \\
$2 \%$ & Scenedesmus sp., & 0.16 & 10 & 16 & Adamsson, 2000 \\
$0.60 \%$ & Spirulina sp., & 2.32 & 14 & 166 & Feng \& Cheng, 2006 \\
$0.80 \%$ & Spirulina sp., & 0.81 & 7 & 116 & Chang et al., 2013 \\
$0.8 \%$ SHU & Spirulina sp., & 0.75 & 7 & 107 & Chang et al., 2013 \\
$1 \%$ & Chlorella sp., & 0.6 & 21 & 29 & Jaatinen et al., 2019 \\
\hline
\end{tabular}

\section{CONCLUSION}

This study concluded that the HU was suitable for the production $(0.57 \mathrm{~g} / \mathrm{L})$ of microalgae Scenedesmus sp., at 10-15\% dilution with significant productivity $(81 \mathrm{mg} / \mathrm{L} /$ day $)$. HU can serve as a cheap nutrient medium for sustainable biomass production eventually bring down the cost of their value-added products. Further studies are needed for cost analysis and nutrient manipulation for better biomass production.

\section{ACKNOWLEDGMENTS}

This research was funded by Research and Technology Transfer, Office of Research Directorate, Addis Ababa Science and Technology University, Ethiopia.

\section{REFERENCES}

Adamsson, M. (2000). Potential use of human urine by greenhouse culturing of microalgae (Scenedesmus acuminatus), zooplankton (Daphnia magna), and tomatoes (Lycopersicon). Ecological Engineering, 16(2), 243-254.

Chang, Y., Wu, Z., Bian, L., Feng, D., \& Leung, D. Y. (2013). Cultivation of Spirulina platensis for biomass production and nutrient removal from synthetic human urine. Applied energy, 102, 427-431.

Cordell, D., Drangert, J. O., \& White, S. (2009). The story of phosphorus: global food security and food for thought. Global environmental change, 19(2), 292-305.

Erisman, J. W., Sutton, M. A., Galloway, J., Klimont, Z., \& Winiwarter, W. (2008). How a century of ammonia synthesis changed the world. Nature Geoscience, 1(10), 636-639.

Fasaei, F., Bitter, J. H., Slegers, P. M., \& van Boxtel, A. J. B. (2018). Techno-economic evaluation of microalgae harvesting and dewatering systems. Algal Res 31: 347-362.

Feng, D. L., \& Wu, Z. C. (2006). Culture of Spirulina platensis in human urine for biomass production and $\mathrm{O} 2$ evolution. Journal of Zhejiang University Science B, 7(1), 34-37.

Gelebo, G. G., Tessema, L. H., Kehshin, K. T., Gebremariam, H. H., Gebremikal, E. T., Motuma, M. T., ... \& Suresh, A. (2020). Phycoremediation of synthetic dyes in an aqueous solution using an indigenous Oscillatoria sp., from Ethiopia. Ethiopian Journal of Sciences and Sustainable Development, 7(2), 14-20.

Jaatinen, S., Lakaniemi, A. M., \& Rintala, J. (2016). Use of diluted urine for cultivation of Chlorella vulgaris. Environmental technology, 37(9), 1159-1170.

Kirchmann, H., \& Pettersson, S. (1994). Human urine-chemical composition and fertilizer use efficiency. Fertilizer research,40(2), 149154.

Levasseur, W., Perré, P., \& Pozzobon, V. (2020). A review of high value-added molecules production by microalgae in light of the classification. Biotechnology advances, 41, 107545 .

Liu, C. H., Han, M. Y., \& Zhang, L. X. (2008). The effects of fertilizer application at early summer on growth, yield, and quality of Fuji

40 | This work is licensed under a Creative Commons Attribution 4.0 International License. 
apple in Weibei Highland. Agricultural Research in the Arid Areas, 26(1), 124-137.

Suresh, A., \& Benor, S. (2020). Microalgae-based biomass production for control of air pollutants. In From Biofiltration to Promising Options in Gaseous Fluxes Biotreatment (pp. 345-372). Elsevier.

Suresh, A., Tamilvanan, S., Harini, K., Seventhi, H. V., Deepan Guna, R., Mahalakshmi, R., ... \& Thenmozhi, M. (2019). Feasibility of cattle urine as nutrient medium for the microalgal biomass production. Global Journal of Environmental Science and Management, 5(4), 441-448.

Tuantet, K., Temmink, H., Zeeman, G., Janssen, M., Wijffels, R. H., \& Buisman, C. J. (2014). Nutrient removal and microalgal biomass production on urine in a short light-path photobioreactor. Water research, 55, 162-174.

Van Vuuren, S. J. (2006). Easy identification of the most common freshwater algae: a guide for the identification of microscopic algae in South African freshwaters. Resource Quality Services (RQS).

Viskari, E. L., Grobler, G., Karimäki, K., Gorbatova, A., Vilpas, R., \& Lehtoranta, S. (2018). Nitrogen recovery with source separation of human urine-preliminary results of its fertiliser potential and use in agriculture. Frontiers in Sustainable Food Systems, 2, 32.

Wilkie, A. C., Edmundson, S. J., \& Duncan, J. G. (2011). Indigenous algae for local bioresource production: Phycoprospecting. Energy for sustainable development, 15(4), 365-371.

Xin, C., Addy, M. M., Zhao, J., Cheng, Y., Cheng, S., Mu, D., ... \& Ruan, R. (2016). Comprehensive techno-economic analysis of wastewater-based algal biofuel production: A case study. Bioresource technology, 211, 584593.

Yang, C., Li, M., Yu, C., \& Liu, H. (2008). Consumption of nitrogen and phosphorus in human urine by Spirulina platensis. International journal of biotechnology, 10(1), 45-54.

Yang, C., Wei, D., \& Zhuang, F. Y. (2008). The force induced by organelles' weight in the microfilament is in the range of $0.1-1 \mathrm{pN}$. Acta Astronautica, 63(7-10), 923-928.

Yang, J., Xu, M., Zhang, X., Hu, Q., Sommerfeld, M., \& Chen, Y. (2011). Life-cycle analysis on biodiesel production from microalgae: water footprint and nutrients balance. Bioresource technology, 102(1), 159-165

\footnotetext{
41 This work is licensed under a Creative Commons Attribution 4.0 International License.
} 